\title{
Silencio o blasón. Escribir entre dos extremos ${ }^{1}$
}

\author{
José Luis Gastañaga Ponce de León \\ Bryn Mawr College
}

El silencio escuda y suele encobrir

la[s] falta[s] de ingenio y torpeza de lenguas;

blasón que es contrario, publica sus menguas

a[1] quien mucho habla sin mucho sentir.

Los versos acrósticos que acompañan la Celestina desde la edición de Pedro Hagenbach salida en Toledo en 1500 son un paratexto preliminar que nos explica por qué es oportuno publicar la obra. Los versos de estas estrofas acrósticas retoman los mismos temas que nos encontramos en la carta prólogo que abre el libro. Sean una respuesta a la carta hecha por una segunda persona, como quiere Di Camillo ${ }^{2}$, o un mensaje atribuible a la voz autorial, lo cierto es que hay varias razones para poner en correlación estos versos con el conjunto de la obra. No sólo con la carta prólogo o los versos finales, sino con toda ella puesto que, como espero demostrar en este ensayo, silencio o blasón, callar o decir, son dilemas que se plantean tanto los personajes al interior del texto como el mismo autor fuera de la fábula. En todos los casos, el dilema tiene siempre un carácter moral y tiene como objeto decidir qué acción debe emprenderse en un momento concreto.

1.- Leí una primera versión de este ensayo durante el seminario Celestina and the Threshold of Modernity auspiciado por la National Endowment for the Humanities (NEH) y dirigido por Michael Gerli durante el verano del 2009 en la Universidad de Virginia.

2.- Ver Di Camillo 2001. Para una exposición más reciente de sus tesis, Di Camillo 2010. Es inevitable coincidir con este crítico en que existe una considerable diferencia en calidad cuando pasamos de la carta prólogo a los versos acrósticos. 
Las octavas acrósticas en los preliminares de la Celestina han sido vistas por Dorothy Severin como un anuncio de que el propósito de la obra es ofrecer un remedio al mal de amores y que ese remedio debe tener además una cualidad estética. Para la investigadora, el énfasis está puesto en las dimensiones artística y estética de la obra (1981: 4). En el otro extremo, Marcel Bataillon vio en esta sección, como en otras partes de la obra, una clara indicación de su intención didáctica, formulada en el contexto de una moralidad cristiana ${ }^{3}$.

Para otros, esos preliminares buscaban emparentar la obra con el género de la comedia humanística y por tanto resaltar el hecho de que fue escrita para beneficio moral de sus lectores u oyentes ${ }^{4}$. Así, el texto no solo recuerda su vinculación con ese género sino que, al señalar una utilidad y una justificación para la exposición de unos amores desenfrenados, ofrece al mismo tiempo una respuesta a quienes condenaban la literatura profana. La ventaja de esta postura es que la calidad estética de la obra (sus «dulces razones») no está reñida con su dimensión didáctica.

Por mi parte, quiero volver a la primera de las estrofas de ese poema preliminar y concentrar mi atención en el binomio silencio-blasón. El vocabulario utilizado en los primeros versos es por demás interesante. La palabra silencio nos invita a pensar en cómo se dejan algunas cosas sin decir y cómo otras, en apariencia nunca dichas, resultan visibles después de una lectura prolongada y profunda. Es lo que ocurre, por ejemplo, con el nombre y patria de Fernando de Rojas, que se esconden y se revelan al mismo tiempo. El silencio es, por tanto, una idea relevante. Con todo, la palabra silencio no está sola. En la cuarteta que aquí he aislado se nos presenta el silencio en relación con su opuesto, blasón (entiéndase blasonar, publicar). Para que quede más claro el autor añade "que es contrario». Es en este difícil equilibrio, entre callar y hablar, entre no decir nada o decir demasiado, donde debemos situar esta reflexión que nos ofrece Rojas ${ }^{5}$

3.- Es la tesis principal de "La Célestine» selon Fernando de Rojas. Véase en especial el capítulo "L'auteur parle» (201-225). Sobre el valor prologal de los versos acrósticos y su relación con la tradición literaria puede verse Montoya Martínez.

4.- Sobre la relación de la Celestina con la filosofía moral, ver Canet (1999, entre otros). Sobre la Celestina considerada en el contexto del género de la comedia humanística, ver Lida (37-50) y Canet (1993: 11-43). La comedia humanística no era ajena a esta preocupación moral; tanto el Paulus (c. 1390) de Pier Paolo Vergerio en su prólogo, como el comentario de Leon Battista Alberti a su Philodoxeos fabula (1424), que se abre con la frase «Hec fabula pertinet ad mores», así lo proclaman (v. Grund 2-3 y 72-73). No aparece en la edición de Grund, pero según Stäuble, en La commedia umanistica del Quattocento, el Paulus lleva como subtítulo la fórmula: "comoedia ad iuvenum mores corrigendos» (apud Canet 1993: 20n).

5.- Aunque me inclino a creer en la existencia de un «antiguo autor», en este ensayo considero a Rojas como el autor para efectos prácticos. Para una bien sustentada defensa de Rojas como autor único, ver Miguel Martínez. 
sobre su propio trabajo que ha venido circulando, en manuscrito y quizá en forma de libro impreso ${ }^{6}$.

El universo que nos presenta Rojas está poblado de personajes que con frecuencia se encuentran en la necesidad de escoger entre dos extremos. Ellos conocen la teoría más extendida sobre la acción moral: la del justo medio aristotélico. Razonan su conducta y consideran las consecuencias de sus acciones. No obstante, se deciden siempre por el camino que los llevará hacia un final desastrado, la muerte. No puede, entonces, dejarse de lado el hecho de que los lectores de fines del siglo XV e inicios del siglo XVI verían en el libro una galería de modelos de conducta. En esto tienen razón quienes propugnan una Celestina entendida como lección a contrario de filosofía moral7. Los personajes de Rojas casi siempre escogen la peor opción; el autor, más avisado, opta por el silencio, la no acción que lo lleva a silenciar su voz de autor después de escrito el segundo prólogo y los versos finales de "Concluye el autor»

Los dilemas que enfrentan los personajes son un recurso conocido; no son un elemento origina $1^{8}$. En los apremios de los personajes reconocemos la influencia de Terencio en Rojas. Un ejemplo de la Andria puede mostrarnos rápidamente la influencia de uno en otro
A buena fe, Davo, que no cumple aquí empezar ni des- cuidar, a lo que tengo entendido, del propósito del viejo acerca de este casamiento, el cual, si con maña no se lle- va, dará al través conmigo y con mi amo. Ni sé qué me haga, si complazca a Pánfilo o si crea al viejo. Si a Pánfilo dejo, temo que se pierda; si le ayudo, temo las amena- zas de éste [el viejo], el cual es malo de burlar. Cuanto a lo primero, ya tiene él noticia de estos amores; a mí me tiene sobre ojos, no desbarate el casamiento con algún engaño; si lo siente, soy perdido, o, si le parece, tomará achaque para, con razón o sin razón, dar conmigo en la tahona (Andria I.Iv) $)^{9}$.

6.- Como se sabe, los versos acrósticos aparecen en la edición de Pedro Hagenbach (Toledo, 1500). No está del todo claro que la edición de Burgos de 1499 —la única edición de la Comedia de Calisto y Melibea sin los versos acrósticos- sea la princeps puesto que las evidencias apuntan a que se trata de una edición posterior con un colofón hechizo. De otro lado, la existencia de una versión manuscrita de la Comedia se puede sustentar en la alusión a ella en la epístola "El autor a un su amigo» (Poyán Díaz 6-8 y 11) y en el manuscrito llamado Celestina de Palacio (v. Conde 1997). Suscribo la tesis de Víctor Infantes según la cual la edición de Burgos tendría los preliminares en las páginas iniciales hoy perdidas (Infantes 2010: 30 y ss.).

7.- Ver Canet (1996 y 1999) y antes Lida.

8.- La novedad es encontrarnos con Rojas, el autor, dando vida al mismo dilema en los preliminares de su libro.

9.- Uso la traducción de Pedro Simón Abril descrita en la bibliografía. También aluden a este pasaje Castro Guisasola (86), Lida (129) y Fraker (86). 
Esta cita de la Andria demuestra que hay un componente de dilemas $y$ deliberaciones en el teatro que tiene un vínculo directo con ese debatirse entre dos extremos que es tan frecuente entre los personajes de la Celestina y que tan larga tradición tiene en el teatro y la retórica ${ }^{10}$. Sobre la influencia de Terencio y la comedia humanística en nuestra obra se han escrito páginas interesantísimas ${ }^{11}$, lo que nos falta ahora es ver cuál es el giro que da Rojas a los recursos retóricos aprendidos de la comedia antigua y humanística. Pasar revista a los dilemas o deliberaciones que asaltan a los distintos personajes de la obra nos muestra cómo un viejo recurso teatral cobra nueva vida en un contexto específico: la Castilla de fines del siglo $\mathrm{XV}^{12}$.

Si nos detenemos a pensar en ello, las ideas de medio y extremo aparecen muchas veces a lo largo de la obra, tanto en las piezas preliminares como en el texto propiamente dicho. En boca de los personajes el binomio medio-extremo se acompaña siempre de una reflexión moral

Celestina.- «iPues triste yo! ¡Mal acá, mal acullá: pena en ambas partes! Cuando a los extremos falta el medio, arrimarse el hombre al más sano, es discreción» (Auto 4, p. 150) 13. $^{3}$.

Así, la filosofía o la voz de la razón aparece repartida entre distintos personajes; ninguno es dueño de la verdad: todos citan a Aristóteles en el primer auto y todos a Petrarca en el resto de la obra ${ }^{14}$.

Estos dilemas se presentan en la Celestina muchas veces como debates internos en los que el personaje finalmente reconoce la necesidad de optar por un justo medio como alternativa más sana. Lo vemos en la alcahueta como parte del mismo monólogo que acabo de citar y en otros episodios también:

10.- Para una revisión de la retórica en la Celestina, véase Fraker, en especial lo que dice sobre la figura retórica que aquí nos ocupa, la deliberatio o dubitatio (71). Fraker refiere a Quintiliano (Instituciones oratorias IX 2:19).

11.- Sobre el conocimiento de Terencio por parte de Rojas y el antiguo autor, ver el ensayo ya citado de Fraker (76). En este ensayo se sostiene que el comentario de Donato, con su énfasis en el andamiaje retórico de las comedias de Terencio, pudo ser la fuente que encaminara a los dos autores hacia una concepción retórica de su obra (75).

12.- Sin embargo, como apunta Canet (1997, 2007 y 2008), no debe olvidarse que la Celestina fue un éxito en distintas regiones y ciudades de España. No es irrelevante relacionar ese éxito con situaciones que trascienden la realidad salmantina de Rojas a fines del siglo Xv, como la revolución en la enseñanza universitaria o los problemas que surgen en los centros urbanos que empiezan a crecer.

13.- Indico número de auto y de página según la edición de Dorothy Severin.

14.- Las citas a Aristóteles y a Petrarca se consideran un indicio certero para separar la Celestina primitiva, la obra del primer autor, impregnada de citas de Aristóteles, de la continuación atribuida a Rojas, sembrada de pasajes tomados de la obra de Petrarca. Ver, entre otros, Castro Guisasola y Deyermond. 
Celestina.- ¿Qué haré, cuytada, mezquina de mí, que ni el salir afuera es provechoso, ni la perseverancia careçe de peligro? ¿Pues yré, o tornarme he? ¡Oh dubdosa y dura perplexidad! no sé quál escoja por más sano. En el osar manifiesto peligro, en la cobardía, denostada pérdida. ¿Adónde yrá el buey que no are? (Auto 4, p. 149).

Celestina.- Son enemigas [todas] del medio; contino están posadas en los extremos (Auto 3, p. 144).

Celestina.- $¡ O$ malaventurada vieja, en esto han de parar mis passos! Si muere, matarme han; aunque viba, seré sentida, que ya no podrá sofrir[se] de no publicar su mal y mi cura (Auto 10, p. 245).

Lo mismo que en otros personajes. Por ejemplo, Sempronio y Pármeno:

Sempronio.- ¿Dexarle he solo, o entraré allá? Si le dexo matarse ha; si entro ${ }^{15}$ allá, matarme ha (Auto 1, p. 89).

Sempronio.- Señor, querría yr por cumplir tu mandado; querría quedar por aliviar tu cuitado, tu temor me aquexa, tu soledad me detiene (Auto 2, p. 132).

PÁrmeno.- Señor, más quiero que ayrado me reprehendas porque te do enojo, que arrepentido me condenes porque no te di consejo (Auto 2, p. 135).

Más allá de sus palabras, los personajes no sólo hablan de extremos, también los viven. En el Auto 4, Melibea se muestra como presa de los extremos cuando pasa de rechazar ferozmente a Celestina a la aceptación del recado que ésta le trae. Estos extremos no son los únicos. Lo que a Melibea le ocurre con Celestina le ocurrirá también con Calisto: va a transitar del rechazo más severo a la rendición. Podemos decir entonces que el tema de los extremos aparece en el discurso de los personajes en forma de reflexión (a manera de guía moral) o en forma de justificación (como explicación de una conducta). Ejemplo de lo primero es ese momento en que Celestina dice "Cuando a los extremos falta el medio, arrimarse el hombre al más sano es discreción» (Auto 4, p. 150). De lo segundo, esa ocasión cuando Pármeno dice «más quiero que ayrado me reprehendas porque te do enojo, que arrepentido me condenes porque no te di consejo" (Auto 2, p. 135). Con todo, hay una tercera modalidad en que los extremos aparecen no de manera directa en la reflexión de los personajes o en el momento de justificar una conducta sino que ellos dan sentido a toda una escena, es decir, revisten de sentido un momento del diálogo. Esto ocurre en el primer encuentro entre Calisto y Sempronio, donde cada uno representa una posición extrema con respecto al amor. Aquí se 
nos muestra el amor en sus extremos. De un lado, tenemos el delirio cortesano de Calisto y, del otro, el materialismo naturalista representado por Sempronio y de inmediato por Celestina. Vamos viendo la importancia de estos extremos para el desarrollo de la trama porque si esas dos son las únicas maneras de concebir el amor, entonces no es extraño que Melibea pase de ser divinizada ("ángel disimulado es, que vive entre nosotros») a ser objeto de la pasión mundana de Calisto ("el que quiere comer el ave, quita primero las plumas») ${ }^{16}$.

III

Casi siempre queda claro que optar por el justo medio es lo más sano; no obstante, nuestros personajes no lo hacen y a consecuencia de ello se condenan. La falta de todos ellos consiste precisamente en precipitarse por algún extremo y perder así la vida. Aunque los personajes tienen la idea de un justo medio en la boca, a la hora de actuar se olvidan de ello ${ }^{17}$. El autor no moraliza, nos presenta los extremos para que los lectores saquemos conclusiones. Este es el colegir «la suma para su provecho» que vemos en los preliminares. Es la lección moral lo que vale, tal y como ocurre con toda esa literatura medieval que nos invita a separar la paja del grano o a quitar la corteza para alcanzar el meollo.

Las palabras y las acciones de los personajes expuestas en forma dialéctica relacionan la obra con la filosofía moral y el tema del libre albedrío. Aquí radica la efectividad de estos personajes tanto en el nivel de la intención didáctica del autor como en el nivel, más cercano a nuestra sensibilidad, de eficacia artística. Pensemos en el enfrentamiento entre Pármeno y Celestina en el Auto I. De un lado, tenemos la inexperiencia de Pármeno y sus dudas, también sus ganas de alejarse de su origen innoble, representado por su madre (con lo que anticipa a los pícaros de los siglos XVI y XVII), para arrimarse más bien a la figura de su padre y a la de quien ha venido a sustituirlo, Calisto; relación que en un principio Pármeno exhibe

16.- Los ejemplos que he dado (de los autos 1, 2, 3, 4 y 10) son del texto de la Comedia. Esto me lleva a pensar que el procedimiento o tema que comento es indesligable del plan original de continuación o conclusión del primer auto. En el auto 17, sin embargo, aparece esta idea de salirle a uno «alas y lengua». Con estas palabras, Elicia se refiere a cómo el humilde Sosía, aguijado por la promesa de ser el nuevo amante de Areúsa, se olvida del establo y los arados para empezar a hablar como un galán enamorado (Auto 17, p. 309). Por supuesto, nos recuerda a las alas que puso la jactancia en la hormiga de la primera estrofa de los versos acrósticos. Algo similar ocurre más tarde, cuando Areúsa le advierte a Sosía que guardar silencio es una virtud: "para esto te dio Dios dos oýdos y dos ojos y no más de una lengua, porque sea doblado lo que vieres y oyeres que no el hablar» (Auto 17, p. 311), que nuevamente remite a la misma primera estrofa de los versos acrósticos.

17.- Quienes han defendido una lectura neoepicureísta de la Celestina han propuesto a Sosia, Tristán, Areúsa, Elicia y a Pármeno en el primer auto como modelos de contención. Ver Consolación Baranda (166-67). 
con orgullo. Frente a él, tenemos la maldad radical de Celestina ${ }^{18}$, su frío cálculo y avaricia. En su esgrima verbal, Pármeno y Celestina revelan su profunda humanidad.

Como señalé antes, en la Celestina no sólo los personajes enfrentan dilemas. Rojas también se retrata a sí mismo en el trance de deliberar. Este dilema que presenta el autor ("contra sí arguye») tampoco es ajeno al discurso dramático ${ }^{19}$. Esta inclinación a la reflexión moral y, sobre todo, el hecho de que el autor participa también de ella, como se aprecia en los versos acrósticos, hacen que el procedimiento se revista de cierta originalidad. Esta novedad alcanza tanto a la Comedia como a la Tragicomedia porque la reflexión que hace Rojas sobre su obra se verifica en dos momentos. En un primer momento, los versos acrósticos justifican la publicación del libro, es decir, la Comedia, tal y como la conocemos en su edición toledana de 1500. En un segundo momento, Rojas vuelve a reflexionar sobre su obra en el prólogo y en las octavas finales de la Tragicomedia. Las variantes que se operan en distintos lugares de los textos editoriales en el tránsito de Comedia a Tragicomedia, aunque tienen interés, no constituyen parte de esta reflexión del autor sobre su obra que vengo comentando. Puesto que se trata de un concepto asociado a la Celestina en los distintos estadios de su redacción, la idea de que el autor debe buscar un justo medio entre dos extremos como un lugar de enunciación me parece una excelente ocasión para construir una interpretación del texto.

Los estudios codicológicos de la edición de Burgos demuestran que los versos acrósticos pudieron muy bien estar siempre junto al resto de la obra impresa; no son un añadido tardío. Víctor Infantes ha demostrado cómo todas las ediciones conocidas los traían. Y aun si no fueran obra de Rojas y se debieran a otra mano, tendríamos que aceptar que son parte de un mismo proyecto y una misma intención. Porque si los versos acrósticos son del editor o impresor, es necesario decir que éste coordina la redacción de los versos con el autor o continuador de la obra. Las coincidencias temáticas entre los acrósticos y el cuerpo de la obra así nos lo hacen pensar.

De otro lado, entre los versos acrósticos existe un dato fundamental para vincularlos con el origen de la Celestina y el contexto cultural en el que ésta se inscribe. Se trata de la procedencia salmantina del primer auto, que es revelada en el poema y no en la carta prólogo. Este dato es imprescindible para calcular el valor de los versos. Como se sabe, Salamanca es un lugar continuamente asociado con la literatura de tema amoroso y las

18.- Aunque no soy partidario de pensar que unos personajes son mejores que otros, la verdad es que Celestina da muestras de una perversidad que no tiene nada que ver con poderes mágicos o intervenciones diabólicas. Estoy pensando en especial en ese pasaje en que le anuncia a Sempronio que se protegerá de los ataques de Pármeno utilizando el recuerdo de la madre de éste "porque de mí queriendo decir mal, tropeçasse primero en ella» (Auto 3, p. 142).

19.- Para la relación entre Terencio y la Celestina, ver Canet 1984. También Fraker (70-78). 
discusiones sobre el amor y el naturalismo amoroso, como demuestran el manuscrito $S$ del Libro de buen amor y los tratados de Alfonso de Madrigal, el Tostado ${ }^{20}$. Precisamente, las primeras muestras de una tratadística dedicada al amor aparecen en el ámbito universitario y en el campo de la filosofía moral (Cátedra 2001: 279).

En estos versos que acompañan y abren la obra, Rojas parece preguntarse: «¿cuál es mi lugar como autor?», «¿qué puedo deciry desde dónde?». Mi intención es mostrar que Rojas opta por un justo medio desde donde emitir un mensaje que, en una lectura didáctica de la obra, sería una invitación a optar por un punto medio como respuesta a los extremos de la locura amorosa. Esta pudo ser la manera en que Rojas o sus editores contrarrestaron la condena de la sensualidad que con frecuencia aparecía en la literatura de ejemplos vitandos. O mejor, es la manera como orientaron la lectura de una historia de amor para neutralizar las críticas de quienes condenaban toda literatura profana, y en particular la amorosa, a priori. Para superar la valla de la censura de sus lectores inmediatos, la versión final de la Comedia lleva esa breve advertencia contra los peligros de la pasión amorosa desmedida. Esto último puede verse como una propuesta generalizada en el libro que opera recubriendo la sensualidad de la obra con las advertencias moralistas de los breves textos que la abren y cierran. Podemos pensar que no fue suficiente lo que hicieron a este respecto los autores y editores de la Celestina puesto que a Cervantes le parecía en 1605 que no se había ocultado bien lo humano.

Incluso podemos ir más allá de la pasión amorosa ${ }^{21}$. Ya que el desastre de Calisto y Melibea incluye la honra familiar, la hacienda y en última instancia la vida, habría que aplicar esta doctrina del justo medio a todos los aspectos de la condición humana. Todo esto puede encuadrarse dentro de la recepción general de la doctrina aristotélica en el siglo XV en Salamanca, que ya hemos aludido. La ética aristotélica tenía en ese tiempo una influencia considerable sobre el derecho y las ideas política ${ }^{22}$.

Esta doctrina habría sido presentada en forma cercana a la comedia humanística primero para una audiencia universitaria y luego, con la imprenta en mente, dirigida a una audiencia más amplia ${ }^{23}$. Esto explica que

20.- Ver Cátedra 1989. Esta línea de investigación se ha visto enriquecida posteriormente con la publicación de un conjunto de textos relativos al tema amoroso relacionados con la Celestina (Cátedra 2001). De otro lado, John Dagenais ha señalado cómo la marginalia de lectores del manuscrito de Salamanca del Libro de buen amor revela un interés en leerlo como ars amandi (162).

21.- La literatura de amore ha sido siempre un medio de abordar los distintos aspectos de la vida; Cervantes es un buen ejemplo de ello.

22.- Para los contactos entre las ideas de Rojas y Fernando de Roa, comentarista de Aristóteles y su maestro en Salamanca, ver Consolación Baranda (119-22 y 125). Para un panorama del pensamiento de Roa, ver Castillo Vegas.

23.- Como vieron en su momento Lida y Severin (2005). 
hacia 1500 hayan aparecido los textos editoriales que acompañan la obra con el propósito de guiar su lectura y recepción. El título fue lo primero en revisarse puesto que la opinión generalizada era que una comedia debía tener final feliz.

En el prólogo de la Tragicomedia la reflexión de Rojas sobre su obra se refiere a haber publicado como Comedia lo que para la mayoría de sus contemporáneos, por su final aciago, tenía carácter trágico. ¿Hizo bien en llamarla "comedia»? ¿A qué llamó "comedia»? Si la Celestina de Palacio representa una tradición manuscrita anterior a la vida impresa de la obra, entonces podemos decir que Rojas mantuvo el nombre "comedia» para su propia continuación o amplificación de los papeles del antiguo autor. Aun si se tratara, en cambio, de una tradición manuscrita paralela a la impresa, seguimos viendo el nombre de "comedia" asociado a la Celestina desde temprano. Los papeles del antiguo autor, es decir, el primer acto, se le han presentado a Rojas como materia cómica, es decir, como comedia humanística dados el dramatis personae y el tema.

Así, tenemos que la Comedia de Calisto y Melibea mostraba su deuda con la tradición terenciana en general y con la comedia humanística en particular en casi todas sus características; sin embargo, en una muy visible, el final, tomaba un giro que la emparentaba más bien con las novelas sentimentales. Pero esta no fue la única de las revisiones y la variedad de ellas nos hace pensar que Rojas introduce modificaciones teniendo en mente no un tipo de lector en particular sino un grupo amplio de lectores. Para ellos se acuña el oxímoron tragicomedia (en el fondo también culto, clásico, pero tan del gusto popular como un baciyelmo); para ellos se escriben los añadidos paratextuales; para ellos se alarga la saga amorosa de Calisto y Melibea; para ellos se publica el texto con ilustraciones. Más tarde, a fines del siglo xvI, saldrá en Salamanca una edición con caracteres modernos, más fáciles de leer que el tipo gótico de las primeras ediciones; $y$, finalmente, este gran público se adueñará de la obra y la llamará Celestina.

IV

Desde el punto de vista del autor, tenemos un libro que se aparta voluntariamente del discurso académico y del discurso ficcional de amore más extendido en su tiempo: la novela sentimental. Es necesario volver a preguntarnos para quién escribe Rojas. No debemos perder de vista que el muy probable primer autor, Rojas y sus editores podrían muy bien haber tenido intenciones diferentes con respecto al libro. Podemos incluso afi mar que distintos editores podían haber hecho lecturas diferentes del sentido del texto. A esto no escapan los traductores, que han dado también 
un color peculiar a sus versiones de la obra ${ }^{24}$. Después de haber hecho esta advertencia podemos intentar responder a la pregunta de para quién se escribió la Celestina. Ya que conocer al público de la obra parece ser tan importante, veamos qué se puede afirmar sobre la audiencia de la Celestina y el entorno universitario que rodea su producción y recepción.

Es muy probable que las versiones primitivas y la Comedia se hayan escrito para una audiencia universitaria, pero no la Tragicomedia de 1502 porque en su prólogo traduce al castellano los textos latinos que cita. El tránsito de Comedia a Tragicomedia nos hace pensar en un libro que quiere encontrarse con el gran público. La obra toda, incluidos los textos editoriales, se aleja poco a poco del humanismo erudito de la carta prólogo. Es verdad que en su escritura y forma de pensar hay resabios de la formación académica y sobre todo jurídica de Rojas ${ }^{25}$, pero en el desarrollo de los diálogos prima el humor y el recurso al habla popular. Encontramos sentencias librescas, sí, muchas, pero expresadas con palabras simples; y son más los proverbios y refranes.

También es posible pensar que Rojas escribe para un ambiente cortesano, el mismo que devoraba las novelas sentimentales. No obstante, esto no se puede sostener porque la obra nos propone una ideología del amor totalmente opuesta a la que defendían esas novelas. Mientras los héroes de la novela sentimental profesan el amor cortés, la religio amoris y el apego a la más noble honra, la Celestina nos propone una ciudad incipiente, una clase alta conformada por jueces y comerciantes y una al parecer inevitable mercantilización de los afectos. Vamos viendo que la Celestina busca un auditorio diferente, más urbano; hecho de estudiantes y profesionales, sí, pero también de un grupo nuevo de lectores nacido de la invención y primeros años de desarrollo de la imprenta ${ }^{26}$. Que la Celestina se difundió ampliamente como libro impreso lo atestiguan sus múltiples ediciones.

Veamos a qué lector en particular pudo haberse dirigido Rojas. Según Pedro Cátedra, la Comedia participa del género de la reprobatio amoris ${ }^{27}$ y se dirige a una persona en concreto (que sería el amigo de la carta prólogo); más tarde, cuando la obra llega a la imprenta se acompaña de los textos

24.- Michael Gerli (211) ha mostrado cómo algunos traductores de la Celestina sintieron la necesidad de atenuar el fatalismo del soliloquio de Pleberio que cierra la obra.

25.- Ver el capítulo «La Celestina y los estudios jurídicos de Fernando de Rojas» en Russell (323-340).

26.- Si se trata de restringir la audiencia del libro habría que pensar en un patriciado o al menos una clase media urbanos, es decir, el sector de la sociedad que debía aprender a cuidarse de «lisongeros y malos sirvientes». En definitiva, quienes tenían educación para leer libros y podían comprarlos.

27.- Eukene Lacarra considera que un lector «cuerdo» leerá la Celestina «como remedia amoris, e incluso como reprobatio amoris» mientras que «el lector loco verá en el proceso amoroso un ars amandi que le invita seguir el ejemplo de los amantes» (18 y 58). 
editoriales que resaltan su carácter didáctico ahora que se enfrenta a una lectoría más amplia. Salir entonces del ámbito universitario supuso para Rojas la necesidad de exhibir sus conocimientos sobre el tema amoroso y, por qué no, sobre su visión del mundo entendido a través de una historia de amor. Lo hizo traduciendo pasajes de Heráclito y Petrarca; pero también lo hizo proponiendo una historia de amor concebida en términos populares. Rojas tuvo que abandonar tanto el universo idealista cortesano representado en la producción y circulación de la novela sentimental (digamos Cárcel de amor) como el medio universitario del cual él mismo proviene. Son dos extremos que a su juicio debe evitar. Salir del ámbito universitario era una acción conocida para Rojas puesto que Nebrija había hecho lo mismo años antes. En su Gramática de la lengua castellana de 1492 la dedicatoria a la reina Isabel hace alusión a trasladar su saber de la «oscuridad» de las aulas salmantinas a la «luz» de la corte de los Reyes Católicos. La diferencia está en que el objetivo de Rojas no es la corte sino la ciudad, el mundo urbano. Una Celestina dirigida a una lectoría aristocrática no hubiera tenido tantas ediciones y además se habría publicado en formato más grande ${ }^{28}$. Si Nebrija tenía una finalidad política, Rojas tendrá una didáctica: sólo una lectura aristotélica del fenómeno amoroso, una consideración hecha a partir de la filosofía natural, podía ofrecer una cura estética al mal de amores. Rojas debía ofrecer a sus lectores lo que la novela sentimental no podía darles. Uno de sus méritos es la adaptación de la comedia humanística al mundo urbano castellano de fines del siglo XV. Nuestra obra tiene sentido sólo cuando abandona el mundo intelectual y libresco donde tiene su origen - tengamos siempre presente al muy erudito y elegante autor de la carta prólogo-y llega a sus lectores citadinos.

La intención es didáctica, por cierto, y no debe extrañarnos por la relación estrecha que existía entre la comedia clásica y humanística, de un lado, y la enseñanza de la filosofía moral, de otro, como nos recuerda Canet en varios de sus artículos. Pero, ¿¿cómo se verifica ese didactismo? Recordemos que Cátedra había planteado la cuestión en términos personales: había un receptor concreto de la Comedia. Esto, que puede ser válido para la etapa más temprana de vida de nuestro libro, deja de tener sentido cuando el libro empieza a circular impreso. La imprenta hace de la Celestina una obra para todos. No pensemos en un público hecho de aristócratas o estudiantes; su autor y sus editores apuntaban a una audiencia mucho más amplia. No es disparatado pensar que los editores de la Celestina tuvieran el propósito de llenar ese vacío denunciado por Melibea: la falta de libros en los cuales aprender modelos de conducta.

Celestina, Pármeno, Sempronio y Calisto mueren de forma súbita. Apenas si Celestina pide justicia antes de morir acuchillada y Calisto al-

28.- Las ediciones descritas por Infantes (2010), fechadas entre 1500 y 1520, son todas en cuarto. 
canza a pedir confesión (aunque sólo en el texto de la Tragicomedia). El único personaje que tiene algo que decir antes de morir, y el tiempo para hacerlo, es Melibea. Sus palabras finales nos invitan a pensar en cómo podrían haberse despedido de este mundo los otros. Melibea pone énfasis en un tema que Cervantes considerará de suma importancia: la libertad de hombres y mujeres para decidir su destino y el carácter contraproducente del encierro de las doncellas. Melibea además subraya el hecho de que la educación recibida ha sido inútil para hacer frente a los embates de la pasión amorosa. Cuando se refiere a "los viejos libros» que le ha dado a leer su padre no debemos esquivar el tema que el personaje, en su momento más dramático, pone sobre la mesa. Existe algo que los viejos libros no pueden enseñar. Las virtudes de la antigua comedia tienen que actualizarse en suelo español.

La redacción temprana de la Celestina está ligada a un entorno erudito, cultivado en el humanismo, acaso universitario. Quien escribe la carta preliminar demuestra ser un lector avezado, seriamente entrenado en el análisis a profundidad de los textos. De otro lado, su lectura estaba lejos de ser un mero entretenimiento. Los pocos lectores tempranos de la $\mathrm{Ce}$ lestina que conocemos no la leyeron sólo como obra de entretenimiento. Los testimonios con que contamos nos muestran lecturas muy serias de nuestra obra. Está el caso del anotador aragonés de la edición de Zaragoza de 1507 —estudiado por Nieves Baranda (2006) - y unos años después el del también anónimo autor de la Celestina comentada, que hace anotaciones eruditas al texto ${ }^{29}$. Otro lector, aunque no precisamente un comentarista, es el Mancebo de Arévalo, descrito por María Teresa Narváez como un criptomusulmán del siglo XVI que al lamentar la pérdida de Andalucía y el duro destino de su gente transcribe un fragmento del prólogo de Rojas, ese que describe el mundo como contienda. Los tres ponen énfasis en la filosofía contenida en el libro y los dos primeros escriben glosas de calidad.

Lo que vengo sosteniendo es que la audiencia de la obra ha cambiado al pasar de una fase manuscrita a otra impresa. Fuera del ámbito universitario para el cual muy probablemente escribió el primer autor, Rojas tenía la necesidad de enfrentar a un público más amplio a quien podía ofrecer la obra vestida o parcialmente cubierta de un ropaje moralista. Los términos con los que articula su mensaje son los más conocidos pa-

29.- Ver el capítulo «El primer comentario crítico de La Celestina: cómo un legista del siglo xvi interpretaba la Tragicomedia» en Russell (293-321). 
ra los lectores de la época: la filosofía moral de Aristóteles ${ }^{30}$. La doctrina de la aurea mediocritas se habría presentado como la defensa de un sentido común. Un mensaje que no es ni para cortesanos ni universitarios, sino para la amplia gama de lectores aludida en los textos preliminares. Recordemos que esos textos se refieren a lectores y oidores en general y no hay nada en esas referencias que nos haga pensar en una audiencia universitaria. Esto debería quedar claro por la sola mención de las edades de los lectores. El entorno universitario no sólo lee y escucha, también crea, traduce, comenta y difunde. En contraste, la audiencia prevista en los paratextos es más pasiva que activa. Podemos pensar en "la muchedumbre de galanes y enamorados mancebos» de la carta al amigo y en el amigo mismo, por supuesto, como sugiere Cátedra. Los versos acrósticos hablan de «amantes», "vosotros, los que amáis». Esto en la Comedia (Pedro Hagenbach: Toledo, 1500). En el prólogo que apareció por vez primera con la Tragicomedia (la primera conocida en español es la de Jorge Coci: Zaragoza, 1507; aunque es probable que haya una de Salamanca de 1502) tenemos que hay una multitud de lectores, sobre cuyos diversos pareceres el autor comenta. En esas líneas nos ofrece la imagen de su lector ideal del texto: "Pero aquellos para cuyo verdadero placer es todo, desechan el cuento de la historia para contar, coligen la suma para su provecho, ríen lo donoso, las sentencias y dichos de filósofos guardan en su memoria para trasponer en lugares convenibles a sus actos y propósitos». Es decir, tanto Calisto como Melibea o Pleberio podrían beneficiarse de esta lectura

Queda bastante claro que la enseñanza moral inscrita en el texto debe tener una utilidad práctica. No basta leer, esa lectura debe tener un impacto efectivo en las acciones y en los propósitos de personas reales. Esto se señala muchas veces en los paratextos que abren y cierran la Celestina y es por tanto una intención que debemos atribuir al autor y editores de la obra. Abrazar el punto medio permite al autor plantear la gravedad del negocio que sus personajes ponen en marcha así como dejar en claro que los personajes actúan movidos por su propia voluntad y son en última instancia los únicos responsables de sus actos. No es entonces un didactismo sin más; se trata de un didactismo nacido de una postura filosófic y de una consiguiente actitud ética.

Según veo las cosas, la brujería supuesta o real cumple el papel de hacer más grave la falta de Calisto y Melibea; con todo, no impide que a nuestros ojos los personajes sean responsables de sus actos y que sus muertes, todas ellas violentas, se perciban en última instancia como justas. Importaba que los lectores vieran en los amores de Calisto y Melibea la más grave falta posible. Que Calisto sedujera a Melibea ya era una falta

30.- El corpus de la filosofía moral que se enseñaba en la universidad en la época de Rojas estaba constituido fundamentalmente por Aristóteles (Ética a Nicómaco, Política y Retórica), Cicerón (Orador) Boecio (Consolación de la filosofía), Jenofonte (Memorias de Sócrates) y Petrarca (De remediis utriusque fortuna) (Canet 1997: 51). 
(puesto que se trataba de mujer soltera y virgen); que se ayudase de una vieja alcahueta y además hechicera sólo agravaba la situación. A esto se suma una cadena de acontecimientos negativos (Pleberio y Calisto pierden su honra; Calisto pierde además su hacienda; mueren Sempronio y Pármeno; muere Celestina, etc.) que no hacen sino recordarnos lo que se sigue de las malas acciones puestas en marcha en el primer acto. Esta condena y muerte final de los implicados en el caso sirvió por mucho tiempo como argumento para defender la libre circulación del libro en España. Sólo a fines del siglo xvi los Índices empezaron a sugerir cortes en el texto, justo cuando la vida editorial de la Celestina estaba en franco declive, y la obra no llegó a ser prohibida in toto sino a fines del siglo XVIII. Aunque algunos podían señalar con dedo acusador la sensualidad representada en la obra, la verdad es que se impuso la defensa de quienes veían en el libro lo que su autor declara en los textos preliminares y finales: que su finalidad no es otra que aleccionar. De otro lado, los inquisidores estaban más preocupados por las herejías que por la sensualidad en las historias de ficción. Lectores como el anónimo aragonés glosador de la edición de 1507 y como el autor de la Celestina comentada que mencionamos antes no hacen sino subrayar esto último: que el libro cumplía con una final dad moral. Juan Luis Vives, aunque señala el peligro de que las jóvenes lean el libro, celebra en otro lugar la calidad del mismo. No es el único moralista que se debate entre censurar la sensualidad de la obra y valorar su riqueza artística ${ }^{31}$.

Podemos decir que los comportamientos de nuestros personajes primero se oponen entre sí para luego desmoronarse todos porque, al fin y al cabo, se trata casi siempre de conductas extremas. De ahí concluyo que los personajes ilustran negativamente la necesidad de escoger el justo medio. No lo hacen y por ello mueren. Sólo Areúsa se sustrae a esta ley; curiosamente, quien representa la libertad propia del pícaro. Se ha visto siempre en Pármeno al prototipo del pícaro, pero es Areúsa quien representa de manera más fuerte la individualidad y ausencia de ataduras que caracterizarán a los héroes de la narrativa picaresca. Ningún punto de vista prevalece. Toda opción o camino que emprenden los personajes conduce al error y en última instancia a la muerte ${ }^{32}$.

Comparemos a modo de ejemplo el proceder de Sempronio y Calisto. Ninguno es superior al otro; el primero puede jugar a ser el médico del segundo pero al final ambos comparten una misma muerte. En el Auto 1 vemos a Calisto desempeñar el papel del enamorado de la tradición cortés, que se regodea en su tristeza y se aferra a la religio amoris y luego, ya

31.- Para lo referente a la censura y juicios sobre nuestra obra me he apoyado en el artículo de Donatella Gagliardi.

32.- La muerte como fin último de la dinámica vital de nuestros personajes ha sido estudiada por Michael Gerli en su ya citado libro "Celestina» and the Ends of Desire. Gerli se centra en la irrupción del deseo como la fuerza que los empuja irremediablemente hacia la muerte. 
en el huerto de Melibea, lo veremos dirigirse a su amada con el lenguaje más crudo («Señora, el que quiere comer el ave, quita primero las plumas»). Frente al atribulado Calisto, Rojas nos ofrece a un Sempronio con un discurso totalmente diferente, basado en el naturalismo aristotélico. Pero esta filosofía no es una que Sempronio haya abrazado con honestidad, es sólo una carta que él utiliza porque le permite tomar control de la voluntad de su amo. Más tarde, en casa de Celestina y frente a Elicia, Sempronio pone en funcionamiento el mismo tipo de lenguaje cortesano que antes criticaba en Calisto (Auto 1) y, en el Auto 9, también en casa de Celestina, llama "gentil» a Melibea. ¿Las palabras de Sempronio parodian las de Calisto? Sí, pero no es sólo eso, hay más. Debemos concluir que no hay doctrina que valga, que toda filosofía, en boca de estos personajes, no es más que un camino para llegar a un fin que siempre es material

\section{Conclusiones}

Cuando Rojas sopesa las distintas opiniones en contienda sobre su obra, no se inclina por ninguna de ellas. Tampoco tiene el mal gusto de imponer la suya. Su decisión es del más profundo eclecticismo: entre los que sostienen que sea comedia y quienes que sea tragedia, propone el híbrido de tragicomedia, en el que encuentra un justo medio que le permite atender a ambos tipos de lectores y satisfacer distintas expectativas de lectura. Más que la integridad del título original, debía importarle la presentación de un caso verosímil. La necesidad de construir una literatura didáctica a base de ejemplos concretos debía ser, a la vez, un reto y una invitación para los autores que a fines del siglo XV veían en la imprenta una oportunidad de intervención pública que les permitiera llegar a un público amplio con un mensaje meditado. Rojas debió ser uno de ellos y lo que se planteó hacer con la Celestina era precisamente poner en forma de diálogo literario, según el modelo de la comedia humanística, la doctrina moral más extendida en su tiempo: la filosofía moral aristotélica. Es la doctrina del justo medio, que debía transitar de las aulas universitarias a las manos, y oídos, de hombres y mujeres ajenos al mundo académico. Entre callar o decir demasiado, entre silencio o blasón, Rojas ha encontrado el punto medio: presentar una situación muy realista e invitar a sus lectores y oidores a colegir «la suma para su provecho». 


\section{Obras citadas}

Baranda Leturio, Consolación (2004), La "Celestina" y el mundo como conflicto, Salamanca, Universidad de Salamanca.

Baranda Leturio, Nieves (2006), "El lector en su tiempo: marginalia a la Tragicomedia de Calisto y Melibea (Zaragoza, 1507)", en Ad amicam amicissime scripta. Homenaje a la profesora $M^{a}$ José López de Ayala y Genovés, Madrid: UNED. II, 191-200.

Batallion, Marcel (1961), La "Célestine» selon Fernando de Rojas, París, Didier.

Di Camillo, Ottavio (2001), «La péñola, la imprenta y la doladera: Tres formas de cultura humanística en la Carta 'El autor a un su amigo' de La Celestina», en Silva: Studia philologica in honorem Isaías Lerner, eds. Isabel Lozano Renieblas y Juan Carlos Mercado, Madrid, Castalia. 111-26.

- (2010), "When and Where Was the First Act of La Celestina Composed? A Reconsideration", en "De ninguna cosa es alegre posesión sin compañian: Estudios celestinescos y medievales en honor del profesor Joseph Thomas Snow, Tomo I: Estudios celestinescos, ed. Devid Paolini, New York, NY: Hispanic Seminary of Medieval Studies. 91-157.

Canet Vallés, José Luis (1984), "La Comedia Thebayda y la Seraphina», en Teatros y prácticas escénicas. I: El Quinientos valenciano, coord. M. V. Diego Moncholí, Valencia: Institució Alfons el Magnànim. 283-300.

- (1993), De la comedia humanística al teatro representable, Valencia, Universitat de València.

- (1996), "Los penitenciales. Posible fuente de las primitivas comedias en vulgar», Celestinesca 20 (1996): 3-19.

- (1997), "La Celestina y el mundo intelectual de su época», en Cinco siglos de "Celestina»: Aportaciones interpretativas, eds. Rafael Beltrán y J. L. Canet, Valencia, Universitat de València. 43-59.

- (1999), «La filosofía moral y la Celestina», Ínsula 663 (1999): 22-24.

- (2007), «Celestina: 'Sic et non': ¿Libro escolar-universitario?», Celestinesca 31 (2007): 23-58.

- (2008), "La Celestina en la 'contienda' intelectual y universitaria de principios del XVI», Celestinesca 32 (2008): 85-108.

Castillo Vegas, Jesús Luis (1987), Política y clases medias. El siglo xV y el maestro salmantino Fernando de Roa, Valladolid, Universidad de Valladolid.

Castro Guisasola, Florentino (1924), Observaciones sobre las fuentes literarias de "La Celestina", Madrid, Revista de Filología Española, Anejo v.

CÁtedra, Pedro (1989), Amor y pedagogía en la Edad Media: Estudios de doctrina amorosa y práctica literaria, Salamanca, Universidad de Salamanca.

CÁtedRa, Pedro et al. (2001), Tratados de amor en el entorno de "Celestina": siglos XV y XVI, Madrid, Sociedad Estatal España Nuevo Milenio.

Conde, Juan Carlos (1997), «El manuscrito II-1520 de la Biblioteca de Palacio: balance y estado de la cuestión", en Cinco siglos de "Celestina": 
Aportaciones interpretativas, eds. Rafael Beltrán y José Luis Canet, Valencia, Universitat de València. 161-85.

Dagenais, John (1994), The Ethics of Reading in Manuscript Culture: Glossing the "Libro de Buen Amor", Princeton, Princeton UP.

Deyermond, Alan D. (1975), The Petrarchan Sources of La Celestina [1961], Oxford: Oxford UP.

FRAKER, Charles (1990), "Celestina": Genre and Rhetoric, London, Tamesis.

Gagliardi, Donatella (2007), "La Celestina en el Índice: Argumentos de una censura», Celestinesca 31 (2007): 59-84.

GeRLI, E. Michael (2011), "Celestina» and the Ends of Desire, Toronto, Toronto UP. Grund, Gary R. (2005), Humanist Comedies, edited and translated by Gary R. Grund. The I Tatti Renaissance Library, Cambridge, MA \& London, Harvard UP.

Infantes, Víctor (2010), La trama impresa de Celestina. Ediciones, libros y autógrafos de Fernando de Rojas, Madrid, Visor.

LACARRA, Eukene (2003), "Ars amandi» vs. "reprobatio amoris». Fernando de Rojas y "La Celestina", Madrid, Ediciones del Orto y Universidad de Minnesota.

Lida de Malkiel, María Rosa (1962), La originalidad artística de La Celestina, Buenos Aires, Eudeba.

Miguel Martínez, Emilio de (1996), "La Celestina» de Rojas, Madrid, Gredos. Montoya Martínez, Jesús (2001), "Los versos acrósticos de la edición de la Tragicomedia de Calisto y Melibea, 1507», en Tras los pasos de "La Celestina", eds. Patrizia Botta, Fernando Cantalapiedra, Kurt Reichenberger y Joseph Snow, Kassel, Reichenberger. 23-41.

NARVÁez, María Teresa (1995), "El Mancebo de Arévalo, lector morisco de la Celestina», Bulletin of Hispanic Studies 72.3 (1995): 254-72.

Poyán Díaz, Daniel (1961), Comedia de Calisto y Melibea, Facsímil de la edición de Toledo de 1500, ed. Daniel Poyán Díaz, Cologny-Geneva, Bibliotheca Bodmeriana.

RojAS, Fernando de (1993), La Celestina, ed. Dorothy S. Severin, $7^{a}$ ed., Madrid, Cátedra.

Russell, Peter E. (1978), Temas de la "Celestina" y otros estudios: del Cid al Quijote, Barcelona, Ariel.

Severin, Dorothy S. (1981), "Fernando de Rojas and Celestina: The Author's Intention from Comedia to Tragicomedia de Calisto y Melibea", Celestinesca 5 (1981): 1-5.

- (2005), "Celestina's Audience, from Manuscript to Print», en Selected Papers from the International Congress in Commemoration of the Quincentennial Anniversary of La Celestina, eds. Ottavio di Camillo y John O’Neill, New York, Hispanic Seminary of Medieval Studies. 197-205. Terencio (Publio Terencio Afer) (1947), La Andriana. La Suegra. El atormentador de sí mismo, traducción de Pedro Simón Abril, 2da. ed., Buenos Aires, Espasa-Calpe. 


\section{Gastañaga Ponce de León, José Luis, «Silencio o blasón. Escribir entre dos extremos», Celestinesca 36 (2012), pp. 143-160.}

\section{RESUMEN}

Los primeros cuatro versos del acróstico que acompaña la Celestina como un texto preliminar subrayan la importancia de dos términos, silencio y blasón, callar o publicar, que representan dos extremos frente los cuales el autor debe optar por un punto medio. En este artículo se sostiene que Rojas, en tanto autor de la obra o, al menos, continuador de los papeles del antiguo autor, adapta esa idea tan manida del justo medio aristotélico a su obra en dos niveles. En un primer nivel, hace que sus personajes deliberen entre dos extremos cuando actúan o reflexionan sobre sus acciones. En un segundo nivel, Rojas, como autor, delibera también sobre las consecuencias de publicar el libro (Comedia) y sobre su respuesta a las opiniones surgidas de un primer público lector (Tragicomedia). En la dinámica entre redacción y recepción de su propia obra, Rojas encuentra un punto medio como lugar de enunciación de un propósito didáctico.

PAlabras Clave: Celestina, Fernando de Rojas; acrósticos; audiencia; filosofía moral.

\section{ABSTRACT}

The first four verses of the acrostic poem that accompanies Celestina as a preliminary text stress the importance of two concepts, silencio and blasón, to remain silent or to publish, that represent two extremes from which the author must choose a middle ground. In this article I argue that Rojas, as author of the book or, at least, as a continuator of the manuscript of the first author, adapts Aristotle's well known idea of the golden mean to his own work in two levels. First, he represents his characters deliberating between extremes when they act or when they reflect upon their actions. In a second level, Rojas, as author, also deliberates on the consequences of publishing a book (Comedia) and on the response he can give to the opinions coming from his early audience (Tragicomedia). In the dynamics between writing and reception of his own work, Rojas finds as a place of enunciation a golden mean from which articulate his didactic purpose.

KEY WORDS: Celestina, Fernando de Rojas; acrostic verses; audience; moral philosophy. 